Karim AK, Mohammad JR. SPH OPEN
CRESTED SPILLWAY. Tikrit Journal
Rizgar Ahmed Karim ${ }^{1, *}$
Jowhar Rasheed Mohammad ${ }^{2}$
1Department of Water Resources
Engineering/College of
Engineering/University of Sulaimani-
Sulaimani, Iraq.
2Department of Water Resources
Engineering, College of Engineering,
University of Duhok, Duhok, Iraq.

Keywords:

2D-SPHysics, Hydrodynamics, Ogeecrested Spillway, Open boundary condition, SPH modeling, Water Surface profile.

\section{A R T I C L E I N F O}

\section{Article history:}

Received

13 Aug. 2020

Accepted

20 Aug. 2020

Available online
Tikrit Journal of Engineering Sciences (2021) 28 (2): 137-151 available online at: http://www.tj-es.com

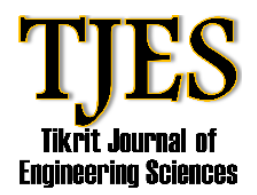

\title{
SPH \\ Open \\ Boundary \\ Simulation of Free-Surface \\ Flow \\ Over \\ Ogee-crested Spillway
}

\begin{abstract}
A B S T R A C T
This study was conducted to compare water surface profiles with standard ogeecrested spillways. Different methods were used, such as (experimental models, numerical models, and design nomographs for the United States Army Corps of Engineers, USACE). In accordance with the USACE specifications, three different models were constructed from rigid foam and then installed in a testing flume. The water surface profile has been recorded for these models with different design heads. For modeling the experimental model configurations, a numerical model based on the smoothed particle hydrodynamics (SPH) technique was used and is developed to simulate the water surface profile of the flow over the ogee-crested spillway. A 2D SPHysics open-source software has been used in this study, using the SPH formulation to model fluid flow, developing the SPH boundary procedure to handle open-boundary simulations, and modifying the open-source SPHysics code for this purpose. The maximum absolute difference between the measured and computed results of the water surface profile for all head ratios of $\left(\mathrm{H} / \mathrm{H}_{\mathrm{d}}\right)$, does not exceed $4.63 \%$ at the crest region, the numerical results for the water surface profile showed good agreement with the physical model results. The results obtained experimentally and numerically by SPH are compared with the CFD results in order to be more reassuring from the results. Additional comparisons were made using interpolated data from USACE, Waterways Experiment Station (WES), and design nomographs. The SPH technique is considered very promising and effective for free surface flow applications.
\end{abstract}

(C) 2021 TJES, College of Engineering, Tikrit University

DOI: http://doi.org/10.25130/tjes.28.2.11

\footnotetext{
* Corresponding author: E-mail: rizgar.karim@univsul.edu.iq Department of Water Resources Engineering/College of Engineering/University of Sulaimani-Sulaimani, Iraq.
} 


\begin{abstract}
جسيمات الهيدرودايناميكية المصقولة ذات المحاكاة مفتوحة الحدود لتدفق السطح الحر فوق المسيل مائي ذو قمة أوجي

رزكار "أحمد كريم قسم هندسة الموارد المائية/ كلية هندسة / جامعة السليمانية

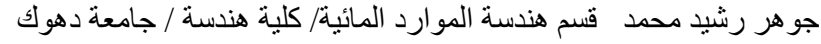

الخلاصة

أجريت هذه الدر اسة بهدف مقارنة ملامح سطح الماء لمسيل مائي ذو قمة أوجي. و استعملت طرق مختلفة، كرئة النماذج التجريبية، النماذج العددية و مخططات

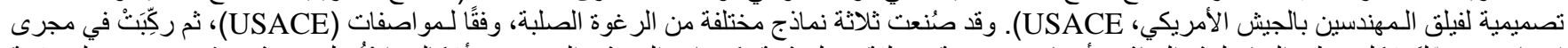

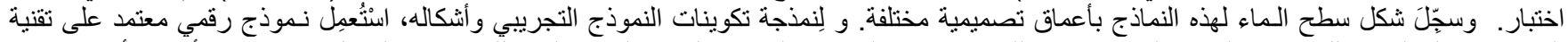

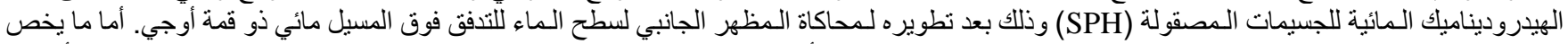

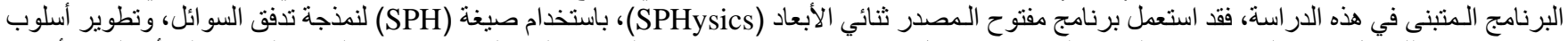

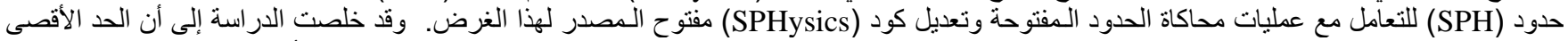

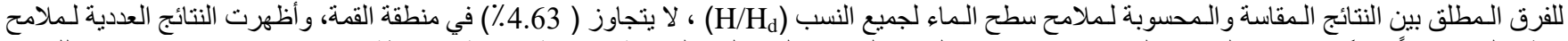

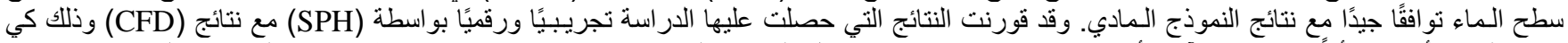

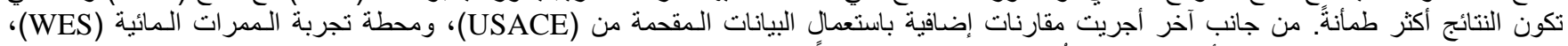

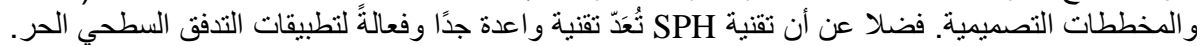

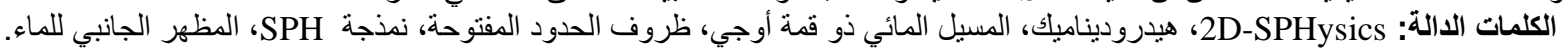

\section{INTRODUCTION}

A spillway is a hydraulic structure usually used in storage and detention dams to release surplus or flood water that cannot be safely stored in the reservoir to prevent damage. Ogee crested spillway is one of the most essential and used hydraulic structures due to its excellent hydraulic performance. During the flood season, it can prevent overtopping of the dams and flowing floods efficiently and safely when it is accurately constructed with reasonably good fluid measuring facilities. On the other side, this structure's improper design can cause dam breakage, especially for rockfill and earthen dams. Therefore, the spillway must be carefully designed to verify the flow characteristics.

Studying the water flow over a spillway is an important engineering tool to ensure proper design. The USACE-WES had studied spillway flow performance and developed a series of recently updated design charts [1]. Experimental modeling has been the only available analytical tool used as the basis for validating other techniques for over 100 years [2]. To date, new design methods are emerging with recent advances in computational and numerical techniques to determine rapidly varying flow conditions. This development has led to widespread use as a standard design tool of numerical modeling in various engineering disciplines [3].

The numerical approach of hydraulics engineering can be classified into two parts. grid-base methods and mesh-free methods [4]. The smooth particle hydrodynamics (SPH) system is a mesh-free computational modeling approach primarily utilizing free-moving particles. It is therefore prepared with unique advantages of tracking different free surfaces with large deformation and it provides a very promising technique for researching the hydraulic spillway.

This approach was initially introduced by Gingold and Monaghan [5] and Lucy [6] in the field of astrophysics but is now used in the field of hydraulic engineering [7, 8], application in free-surface flows [9]. SPH has been widely used in the coastal hydraulics $[10,11]$, structure dynamics [12], fluid-structure interactions [13, 14], multi-phase flows $[15,16]$ and dam-break flows [17, 18]. Many researchers have attempted to introduce some numerical and experimental methods to solve the field of flow, such as free surface profile [19]. Physical models for several real-life cases were investigated: Shahid Madani Dam's spillway [20], Mandali Dam's ogee spillway [21], and Laleli dam's spillway [22] as examples. It is worth mentioning that the 
recorded results are valid for those particular cases and can only be used as a rough estimate in other similar cases.

The approach is still under development yet a broad range of problems can be modeled. It is used in many applications and incorporated in the well-known open-source program SPHysics [23].

\section{Material and Methods}

\subsection{Experimental Model:}

Varied shapes and designs have been suggested for the ogee spillways. Most of the variations are at the upstream curves of the crest axis. Crest forms were extensively studied in USBR laboratories using experimental data of upstream water depth variations. The upper nappe was measured carefully for different discharges and velocities [24].

(Maynard 1985)[25] revealed the upstream side of the spillways in four different shapes: one vertical and three inclines. The upstream curve profile is a combination of radii proportional to the total pressure head whereas the downstream curve is the arc portion between the crest axis and the tangent point. The upstream vertical face type was standardized via the following equation:

$X^{1.85}=2.0 H_{d}^{0.85} * Y$

Here, $H_{d}$ is the design head above the crest, $X$ and $Y$ are coordinates of the crest profile with their origin that are located at the highest point of the spillway crest, [1]. The
The purpose of the present study is to establish a computational model using Smoothed Particle Hydrodynamics by applying codes (SPHysics-2D-2.2.001) as a new technique for simulating the free surface flow over spillways and to produce numerical results to compare them with the performance results of experimental models.

Cartesian coordinate system ( $\mathrm{x}, \mathrm{y}$, and $\mathrm{z}$ ) described the stream-wise, vertical direction, and span-wise, respectively; $(x, y, z)=(0,0,0)$ at the origin. The $y$-axis is directed in the downward direction.

One of the important goals of this study is to apply the particle approach SPH to model the free surface profile for flow over Ogee crested spillways for different head ratios $\left(\mathrm{H} / \mathrm{H}_{\mathrm{d}}\right)$ in a controlled environment. To this purpose, three experimental models were constructed as shown in Figure (1) with a vertical upstream face and a height appropriate to ensure negligible approach velocity.

The upstream curve of the spillways is composed of three different curves with different radii. The smaller radius curve $\left(\mathrm{R}_{3}=0.04 * \mathrm{H}_{\mathrm{d}}\right)$ is related to the upstream vertical face with the curved portion of the crest; this vertical face was added to eliminate discontinuity of the surface, improved the pressure conditions, and discharge coefficients at heads beyond the design head.

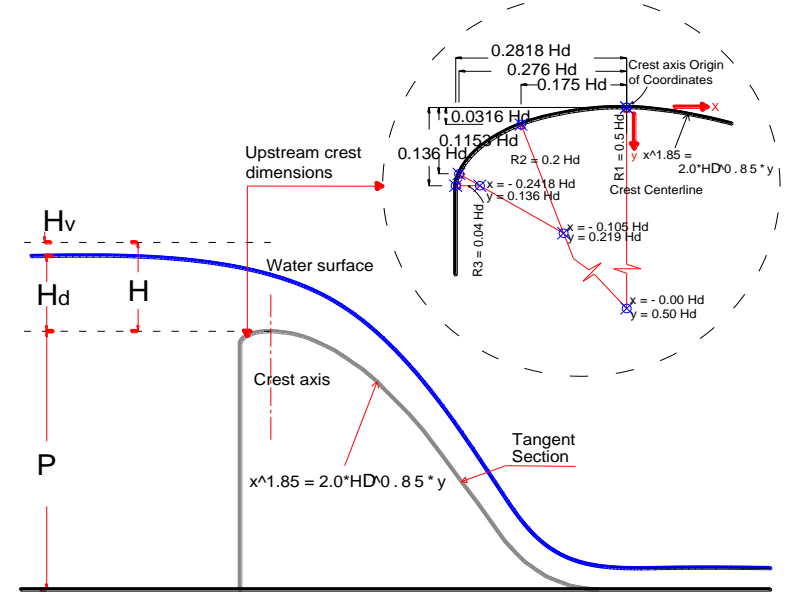

Fig. 1. Dimensions of standard Ogee-crested spillway, [1]

All models were constructed and designed as shown in

Table (1). The equation used for the downstream crest profile

$$
y=\frac{x^{1.85}}{2 H_{d}^{0.85}}
$$

design is of Maynard: 
Table 1

WES Standard Upstream Spillway Quadrant for Vertical Upstream Face

\begin{tabular}{|c|c|c|c|c|c|c|c|c|c|c|}
\hline \multirow{2}{*}{$\frac{\dot{0}}{z}$} & \multirow{2}{*}{ 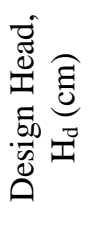 } & \multirow{2}{*}{ 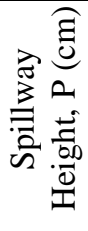 } & \multirow{2}{*}{ 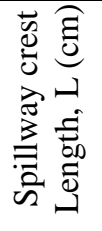 } & \multirow{2}{*}{ 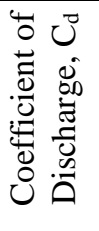 } & \multicolumn{3}{|c|}{$\begin{array}{l}\text { Length of quadrant radii } \\
\qquad(\mathrm{cm})\end{array}$} & \multicolumn{2}{|c|}{$\begin{array}{c}\text { The endpoint of } \\
\text { the downstream } \\
\text { curve }(\mathrm{cm})\end{array}$} & \multirow{2}{*}{ 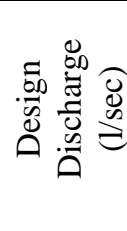 } \\
\hline & & & & & $\mathrm{R}_{1}$ & $\mathrm{R}_{2}$ & $\mathrm{R}_{3}$ & $\bar{x}$ & $\mathrm{y}$ & \\
\hline 1 & 7.5 & 20 & 27.83 & 0.493 & 3.75 & 1.50 & 0.30 & 10.68 & 12.78 & 13.5 \\
\hline 2 & 6.0 & 20 & 26.42 & 0.493 & 3.00 & 1.20 & 0.24 & 8.56 & 14.21 & 9.75 \\
\hline 3 & 3.0 & 20 & 23.62 & 0.493 & 1.50 & 0.60 & 0.12 & 4.27 & 17.11 & 3.40 \\
\hline
\end{tabular}

The experimental models are made of rigid foam and built to conform to the distinctive shape of an Ogee spillway using the computer numerical control machine (CNC). Rigid foam is selected because it can be fabricated with smooth

\subsection{Measuring Techniques}

Each of these models was positioned $4.0 \mathrm{~m}$ away from the upstream end of a test flume. In each process, the flow dynamics were measured and analyzed for three head ratios $\mathrm{H} / \mathrm{H}_{\mathrm{d}}(0.50,1.00$, and 1.33$)$. The flowrate that passed over curves. Each model was installed in the flume at the middle of a glass panel to visualize the process of testing and profile measurements, as shown in Figure (2). the spillway models was measured using the provided electromagnetic flowmeter. Two-point gauges measure the depth of water that passed over the models.

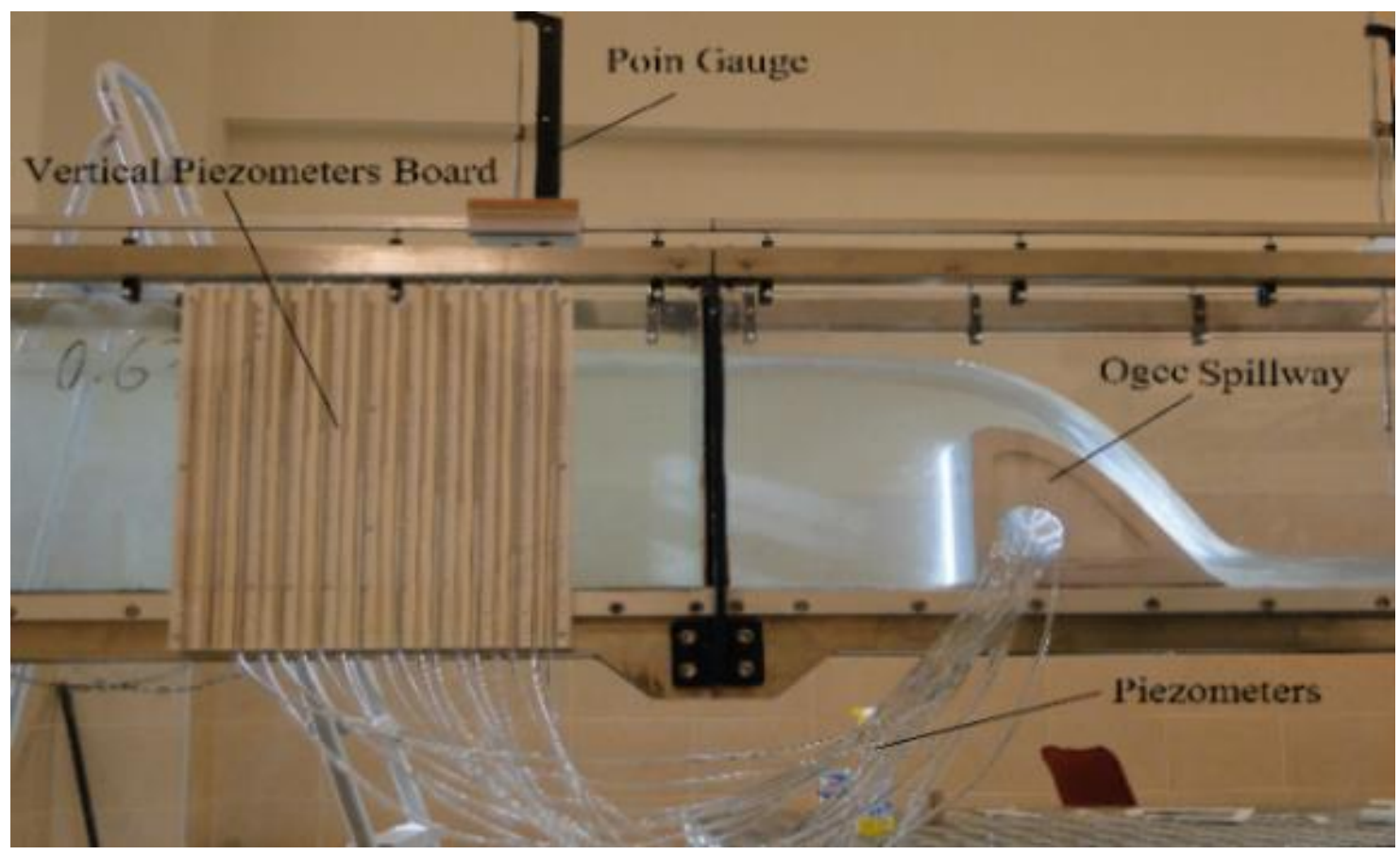

Fig. 2. Side view of the experimental model 


\section{Numerical analysis}

\subsection{Governing equations and computational scheme}

The governing flow equations are given by (JafariNodoushan) including mass conservation and motion in the Lagrangian frame for a weakly compressible flow, [26]:

$$
\begin{aligned}
\frac{D \rho}{D t} & =-\rho \nabla \cdot u \\
\frac{D u}{D t} & =\frac{1}{\rho} \nabla p+F \\
\frac{D x}{D t} & =u \\
p & =k_{o}\left(\left(\frac{\rho}{\rho_{o}}\right)^{\gamma}-1\right) \\
k_{o} & =\frac{c_{o}^{2} \rho_{o}}{\gamma}
\end{aligned}
$$

Equations (5) and (6) refer respectively to the continuity and momentum equations for a 2-D flow occurring in the vertical plane. $t$ is time, $\rho$ is the fluid density, $\left(u=u_{i}+w_{k}\right)$ is the velocity vector with $u$ and $w$ being the respective components along $\mathrm{x}$ and $\mathrm{z}$ directions, $p$ is pressure and $F$ is the external force (per unit mass) acting on the fluid which typically includes a contribution from gravitational acceleration. Equation (7) will be submitted to time integration for tracking the position vector of individual fluid parcels, $x=\mathrm{x}_{\mathrm{i}}+\mathrm{z}_{\mathrm{k}}$, that describes the flow. Equation (8) is referred to as the equation of state (EOS) since it associates a unique value of pressure to the density of each fluid parcel. The exponent $\gamma$ is set to 7 for free surface flows [12]. $\rho_{0}$ is the reference density of the fluid corresponding to $p=0$. It is taken $\rho_{0}=1000 \mathrm{~kg} / \mathrm{m}^{3}$ for water in what follows. The speed of sound at the reference density, $\mathrm{c}_{0}$, is prescribed such that permitted density variations stay to within $1 \% \rho_{0}$ [9]. This requirement is consistent with the nature of assumed weakcompressibility, a feature that enhances the efficiency of the numerical scheme as well.

\subsection{Pre-processing input options of SPH}

Based on many trials, the best initial conditions and geometry construction was considered as follows:

The geometry of spillway models is created by drawing spillway models using AutoCAD in 3D form and exported into Stereo Lithography (STL) format then directly imported into SPHysics code as a complex geometry. The domain length and height are fixed to $2.00 \mathrm{~m}$ and $0.45 \mathrm{~m}$ respectively for all models, also the width and height of the models are fixed to $30 \mathrm{~cm}$ and $20 \mathrm{~cm}$ respectively, as shown in Figure (3). The vertical upstream face of the spillway models is located at $50 \mathrm{~cm}$ from the origin (an inlet of the domain) for all the models. It's worth mentioning that the downstream condition and tailwater depth were not considered in this study.

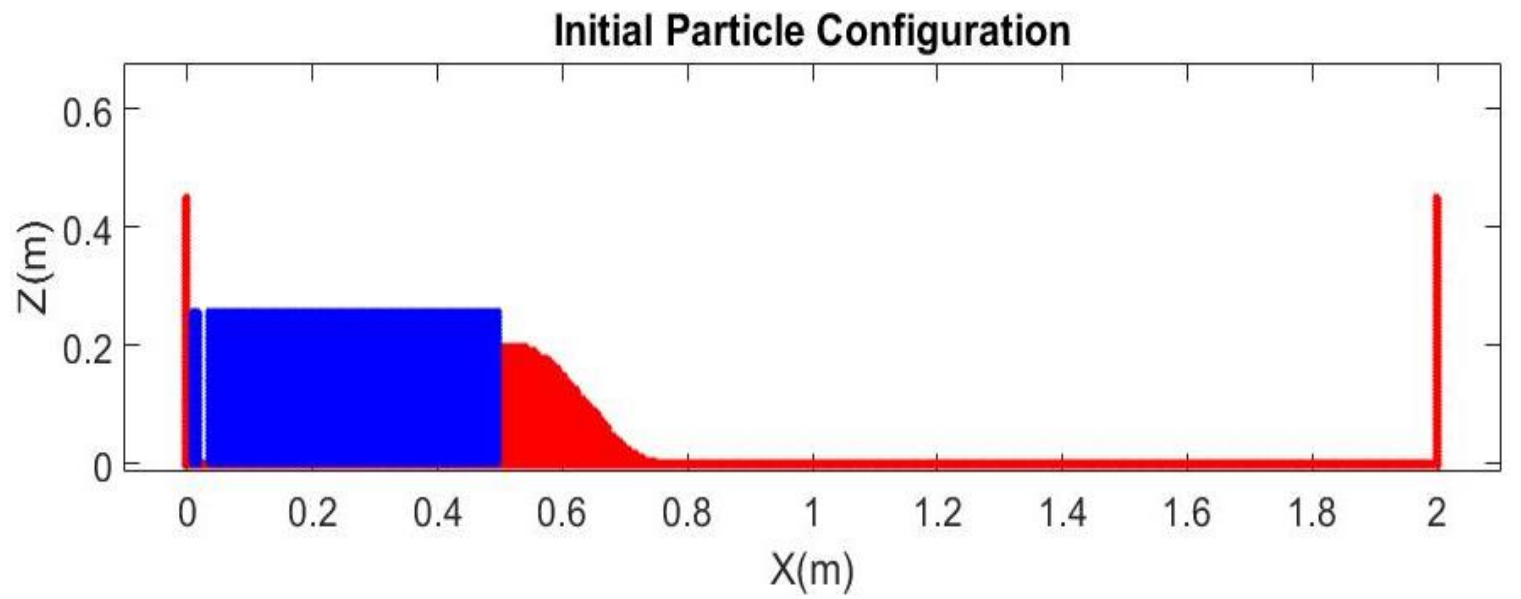

Fig. 3. Initial particle configuration, Model No. 3

The domain is filled with water from the upstream inlet to the vertical upstream face of the spillway model, the best height of filled water is found to be between the water height at the inlet and the height of the spillway crest since the water height in the inlet is considered as the upstream water level for all models. 


\subsection{Final Algorithm Results}

Model No. 1 has been tested for the final algorithm. Figure (4) indicates the simulation process until it reaches a steady-state. The experimental water surface was also drawn for the same run to reassure the results as shown in the last screenshot (green colored line).

\section{Results}

\subsection{Tests of Stability}

The stability of the program must be validated first before the program's outcomes are compared with the experimental

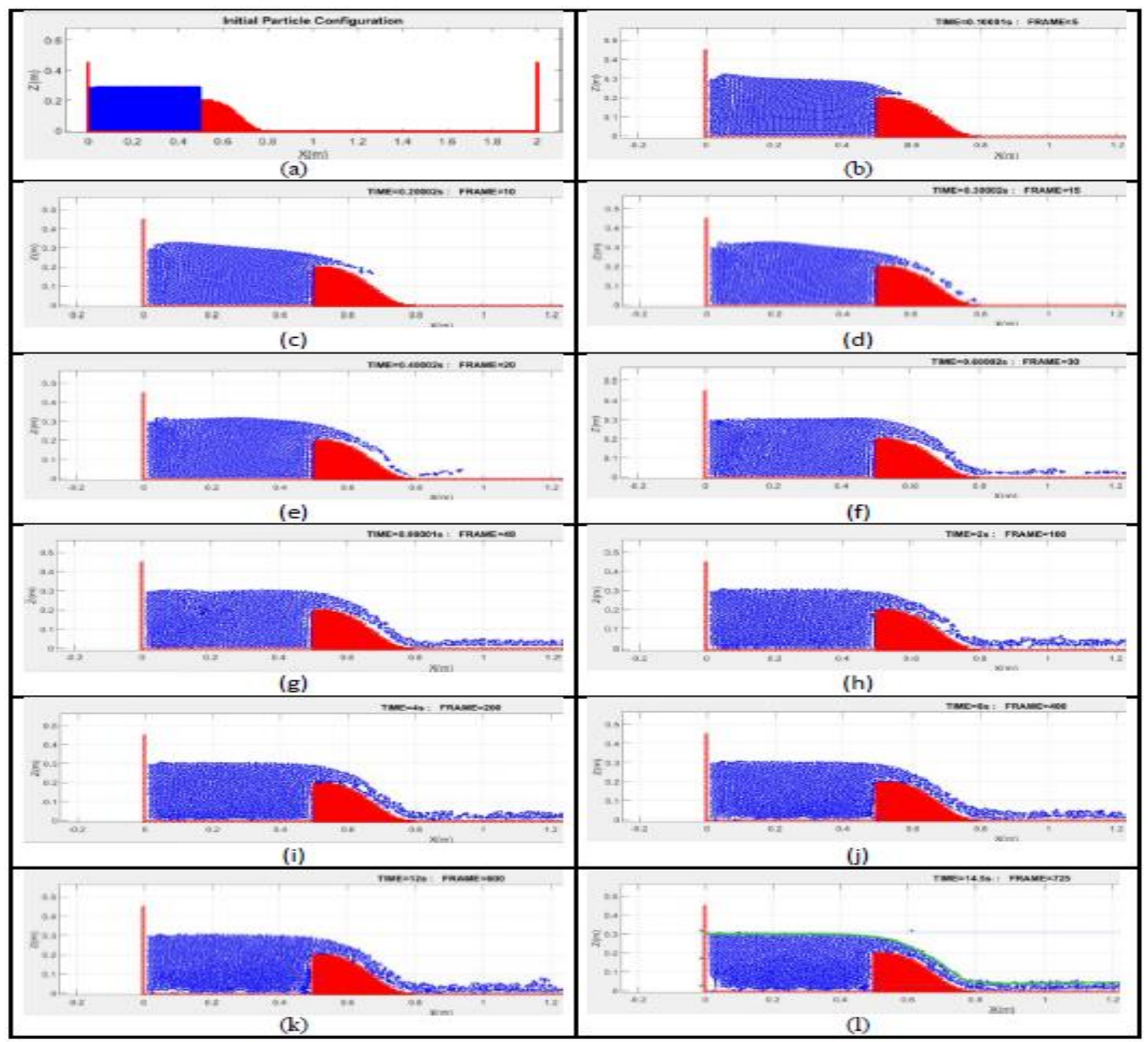

Fig. 4. The simulation process of the final algorithm results, (a) Initial Geometry, (b) at $t=0.1 \mathrm{sec}$, (c) at $t=0.2 \mathrm{sec}$, (d) at $\mathrm{t}$ $=0.3 \mathrm{sec},(\mathrm{e})$ at $\mathrm{t}=0.4 \mathrm{sec}$, (f) at $\mathrm{t}=0.6 \mathrm{sec},(\mathrm{g})$ at $\mathrm{t}=1 \mathrm{sec},(\mathrm{h})$ at $\mathrm{t}=2 \mathrm{sec},(\mathrm{i})$ at $\mathrm{t}=4 \mathrm{sec},(\mathrm{j})$ at $\mathrm{t}=8 \mathrm{sec},(\mathrm{k})$ at $\mathrm{t}=12 \mathrm{sec},(\mathrm{l})$ at $\mathrm{t}=15 \mathrm{sec}$ for model No. 1 , Run No. 3 
At the beginning of the simulation, the condition is unstable after some time the balance between the inflow and the outflow begins, and the steady-state is preserved as shown in Figure (5). Once the steady-state is achieved without errors this means that the program is stable and as a final result, the outcomes after this condition can be dependent The MATLAB routine was written to evaluate performance data to verify program stability. One of the most important tests for ensuring greater stability is the calculation of the discharge in various sections.
The test demonstrates the discharge measurement of four sections inside the domain; the first section is positioned in the center of the buffering layer of the particles $\left(x_{1}=0.02\right.$ $\mathrm{m})$ and the last section is positioned at the origin point of the model crest $\left(\mathrm{x}_{4}=0.525 \mathrm{~m}\right.$, while the other two sections are located between the first and the last sections at an equal distance $\left(\mathrm{x}_{2}=0.1883 \mathrm{~m}, \mathrm{x}_{3}=0.3566 \mathrm{~m}\right)$ as shown in Figure $(5-a)$.

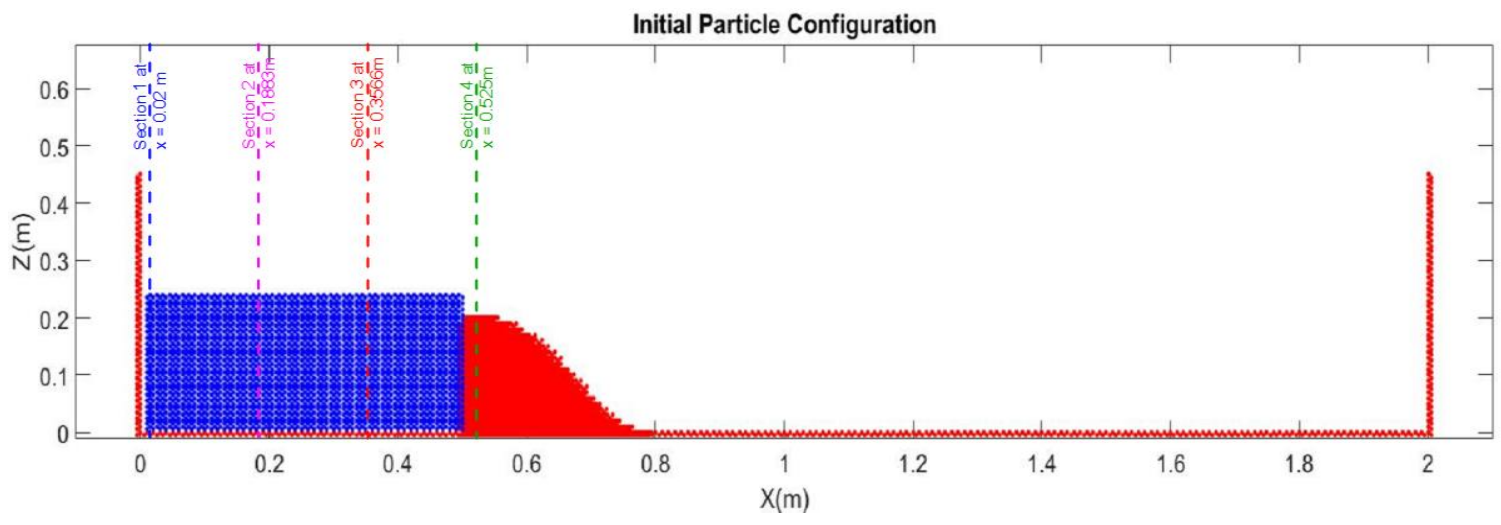

(a) Section Locations

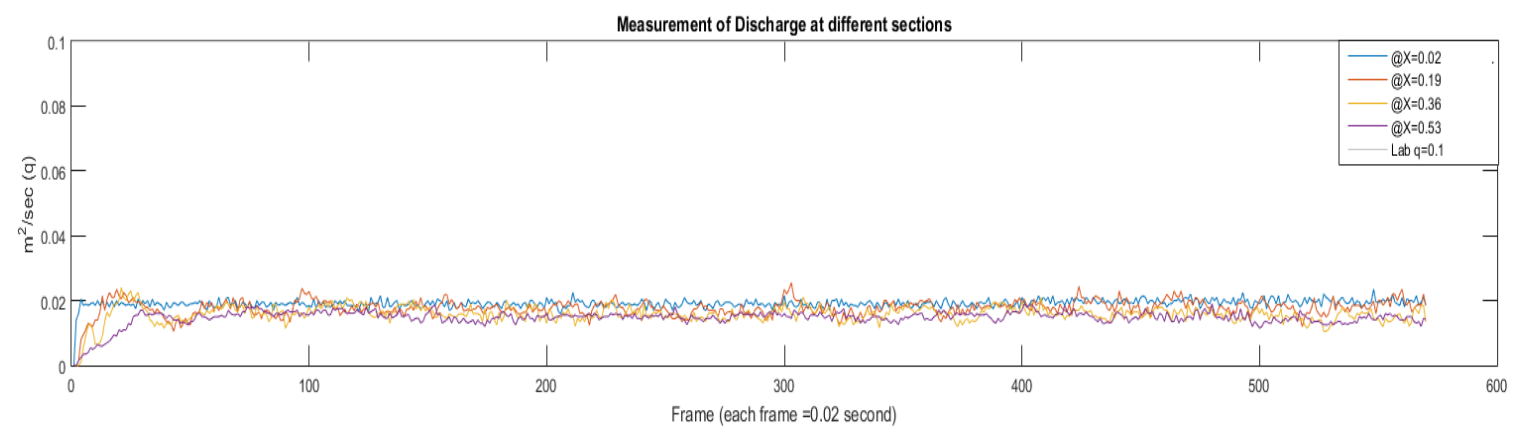

(b) Discharge Values at different sections for $\mathrm{q}=6.25 \mathrm{l} / \mathrm{sec}$

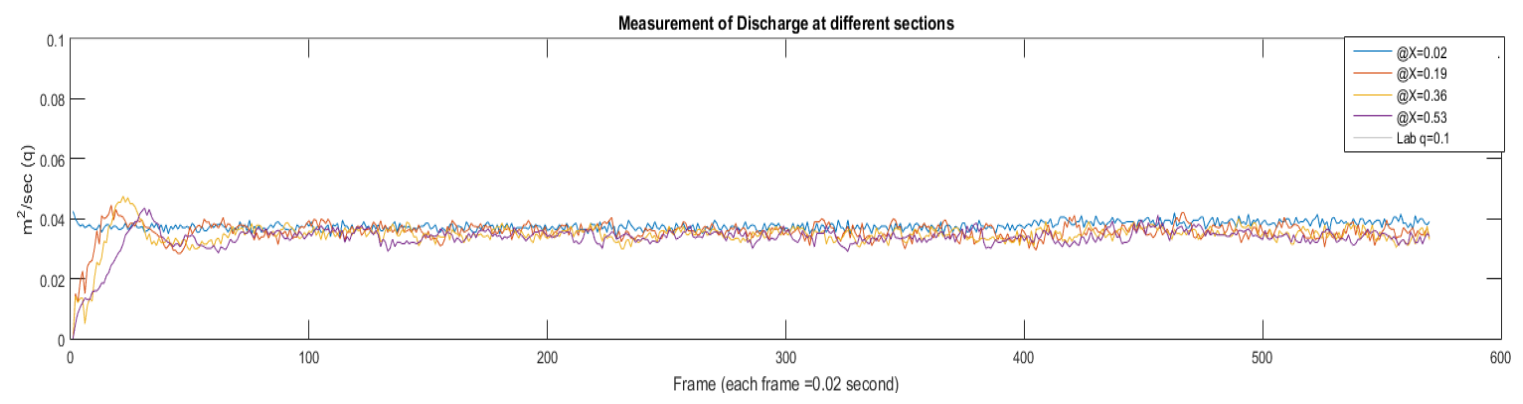

(c) Discharge Values at different sections for $\mathrm{q}=11.49 \mathrm{l} / \mathrm{sec}$ 


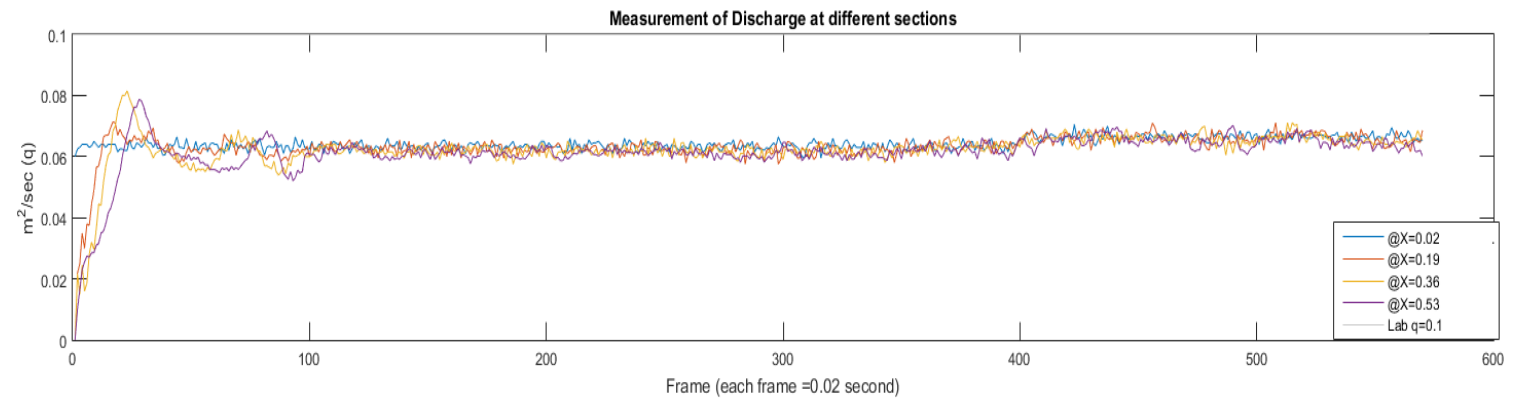

(d) Discharge Values at different sections for $\mathrm{q}=17.65 \mathrm{l} / \mathrm{sec}$

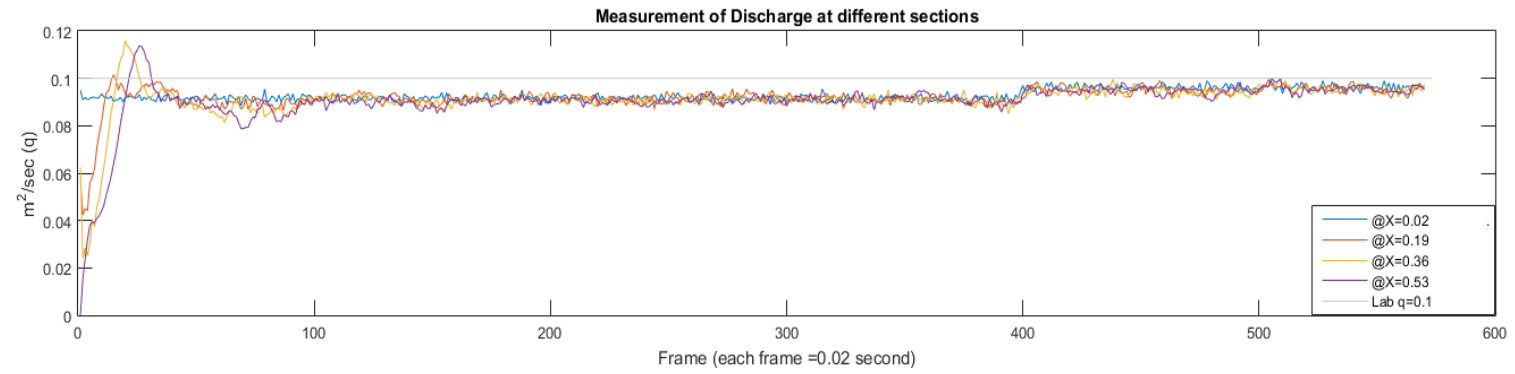

(e) Discharge Values at different sections for $\mathrm{q}=24.72 \mathrm{1} / \mathrm{sec}$

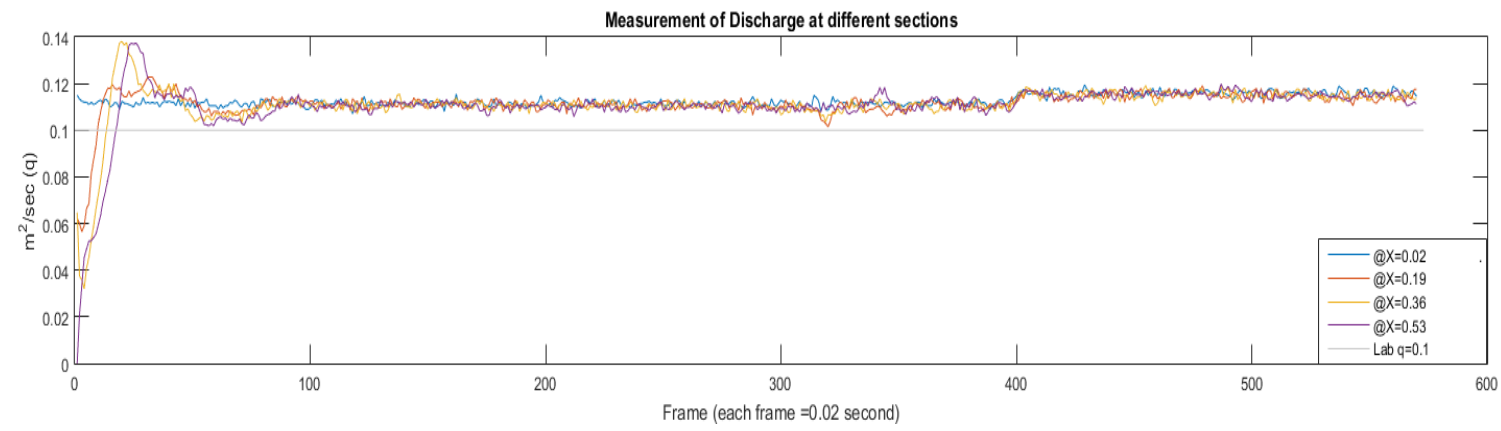

(f) Discharge Values at different sections for $\mathrm{q}=30.0 \mathrm{1} / \mathrm{sec}$

Fig. 5. Simulation results of discharge at different sections

\subsection{Comparison between Experimental and Numerical Results}

In order to clarify the effects on the free surface profile of Ogee crest geometry, rear slope, and toe it is important to look initially at how the numerical SPHysics code applied in this analysis predicts the flow conditions. The numerical 2D SPHysics serial version code is used for the application of the computational smoothed particle hydrodynamics technique. All of the input options were taken into account and the input options for the open boundary, such as water height at the inlet and mean velocity, were also developed.
The properties of the particles could be obtained by running the improved 2D SPHysics codes, the properties consist of coordinates ( $\mathrm{x}$ and $\mathrm{y}$ ) in meter, velocity components ( $u$ and $v$ ) in $\mathrm{m} / \mathrm{sec}$, mass density in $\mathrm{gm} / \mathrm{cm}^{3}$, pressure in Pascal, and mass in gm. These properties are organized according to the particle size in the form of matrices of different dimensions, named (PART), based on the particle size. Such PARTs are generated as a consequence of the simulation process of 2D-SPHysics codes, approximately 50 PARTs are produced at each second 
of simulated time, and each PART consists of a matrix of 7 rows and a very large number of columns as shown in Figure

(6).

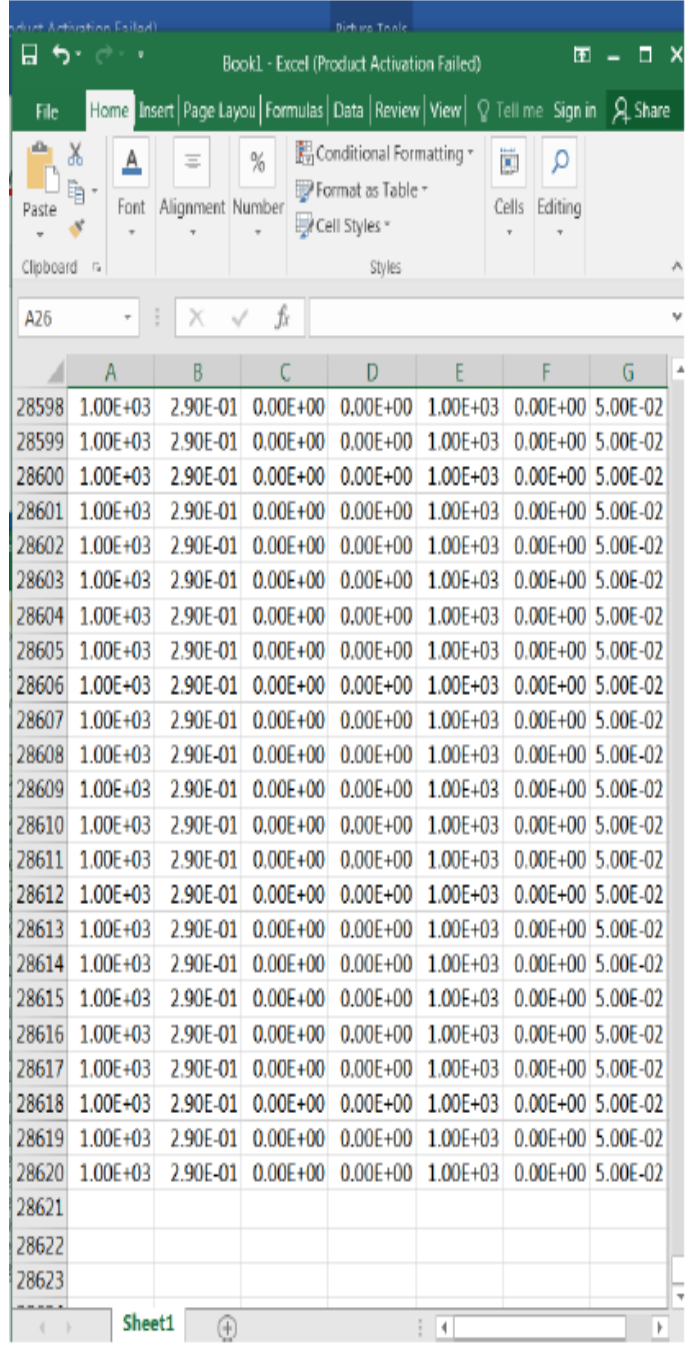

Fig. 6. The properties of the particles produced as a consequence of the SPHysics simulation process

\subsubsection{Water Surface Profile:}

The simulation test is to validate the free surface profile with the experimental results. For this purpose, a Matlab subroutine is written to simulate the outcomes of SPHysics to find the water surface profile. The domain was divided into equally spaced, vertical sections, of $\mathrm{dx}$ width, then within each of these sections, the highest particles were to be found. It is worth noting that the splashed particles of the fluid should not be considered, because they are not represented as a free surface profile, except the particle that is $(3 * d x)$ far away from the particles below it. The coordinates of particles located on the water surface profile are provided a directory from the matrices obtained from the MATLAB code outcomes, as shown in Figure (7). This method was used to compute the water surface profile for all cases in this work because it's the most accurate method. The reference of this accuracy is a participation of more than 10 PARTs in each 
simulation and all of these PARTs were reaches to

the steady state flow condition.

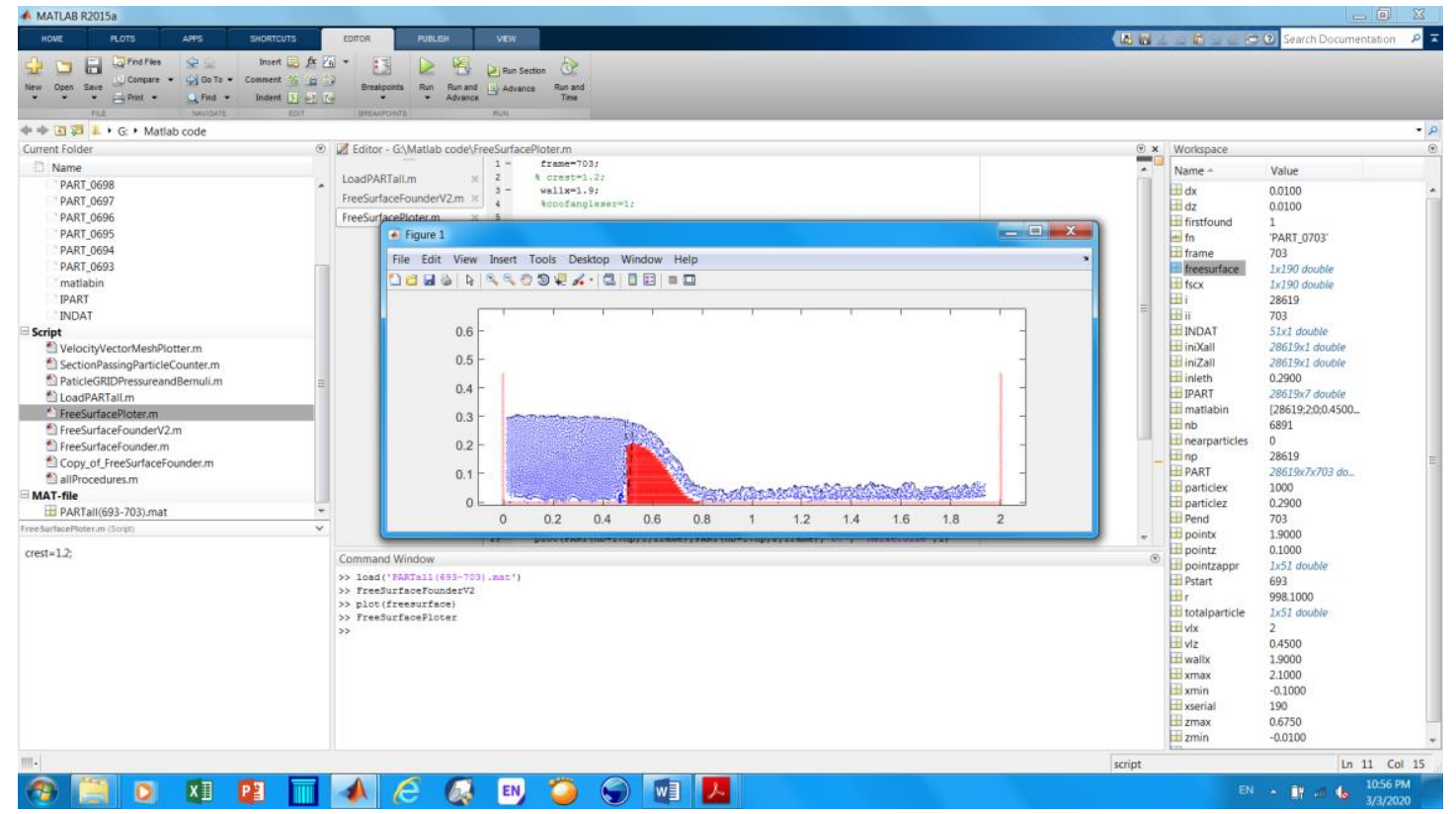

Fig. 7. Matlab subroutine for simulation water surface profile

The water surface profiles under four different upstream pressure heads were investigated along the spillway models surface. Such heads of pressure are

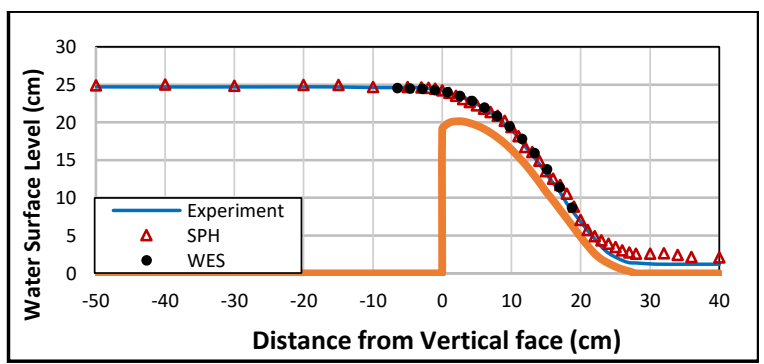

(a) Model No. (1), $\mathrm{H} / \mathrm{H}_{\mathrm{d}}=0.50$

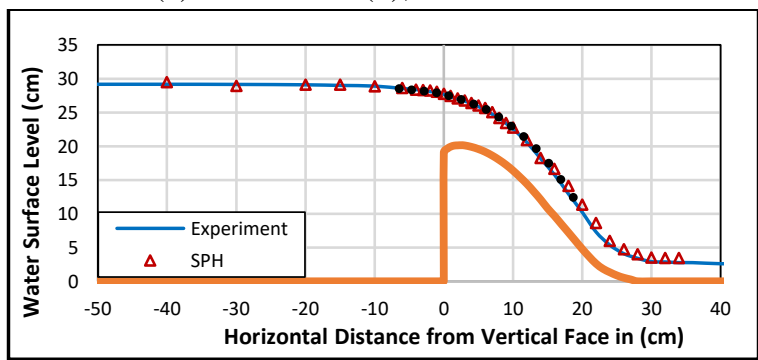

(b) Model No. (1), $\mathrm{H} / \mathrm{H}_{\mathrm{d}}=1.00$ applied based on the design head ratios $\left(0.50 \mathrm{H}_{\mathrm{d}}\right.$, $1.00 \mathrm{H}_{\mathrm{d}}, 1.17 \mathrm{H}_{\mathrm{d}}$, and $\left.1.33 \mathrm{H}_{\mathrm{d}}\right)$. Model No. 1 findings are demonstrated in Figure (8).

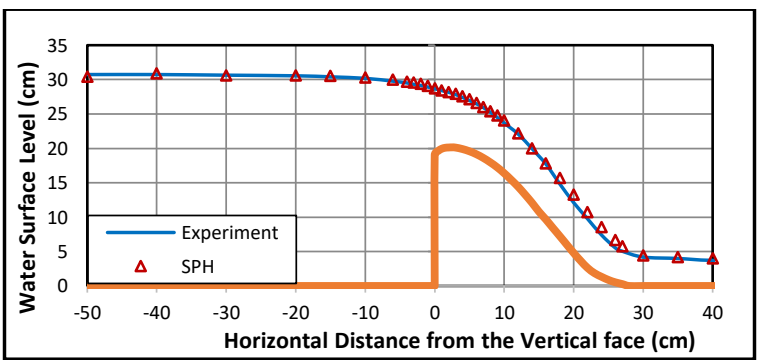

(c) Model No. (1), $\mathrm{H} / \mathrm{H}_{\mathrm{d}}=1.17$

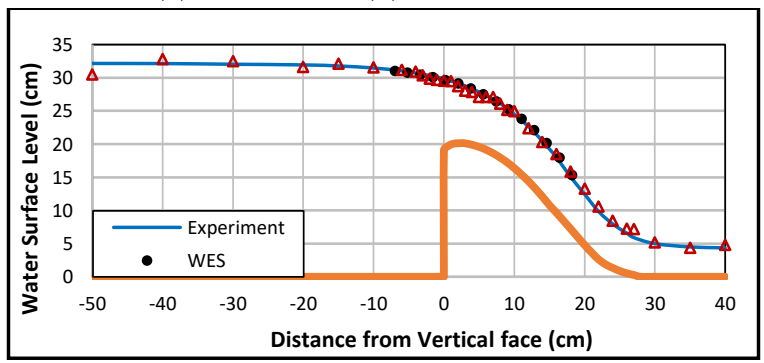

(d) Model No. (1), $\mathrm{H} / \mathrm{H}_{\mathrm{d}}=1.33$

Fig. 8. Comparison between measured and computed water surface profiles for model (1) $(\mathrm{P}=20 \mathrm{~cm}$ and $\left.\mathrm{H}_{\mathrm{d}}=7.5 \mathrm{~cm}\right)$ 


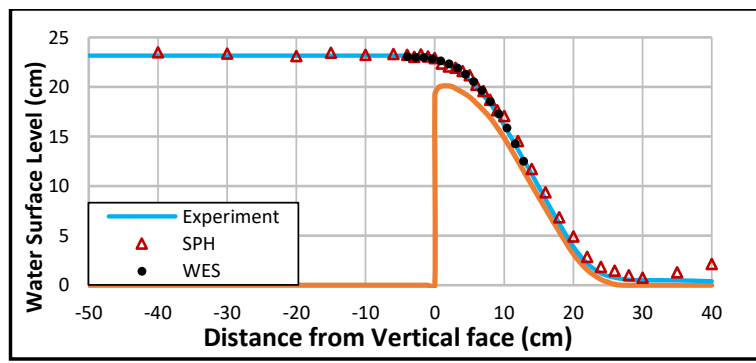

(a) Model No. (2), $\mathrm{H} / \mathrm{H}_{\mathrm{d}}=0.50$

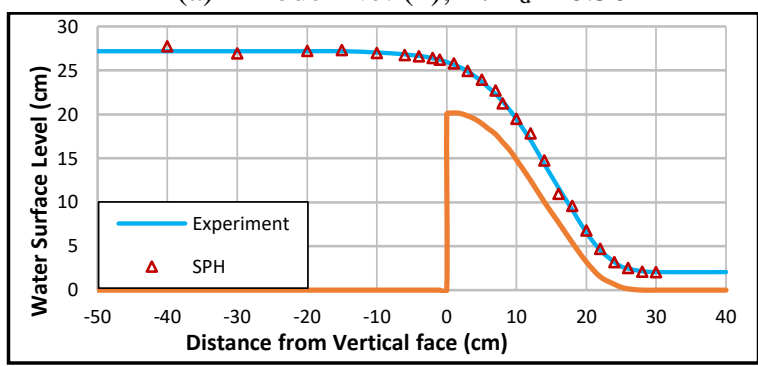

(c) Model No. (2), $\mathrm{H} / \mathrm{H}_{\mathrm{d}}=1.17$

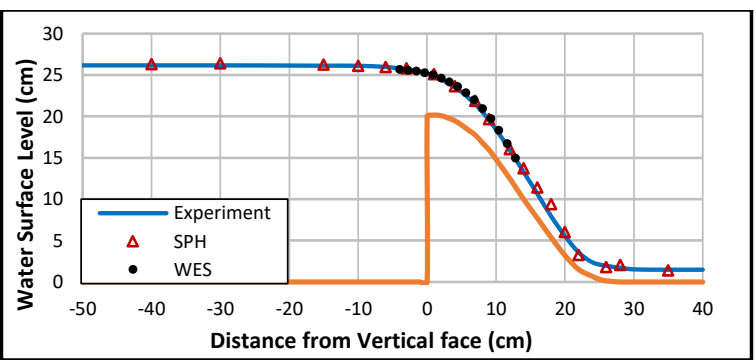

(b) Model No. (2), $\mathrm{H} / \mathrm{H}_{\mathrm{d}}=1.00$

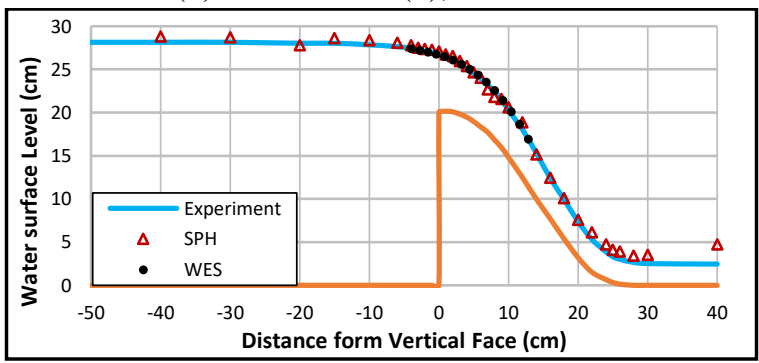

(d) Model No. (2), $\mathrm{H} / \mathrm{H}_{\mathrm{d}}=1.33$

Fig. 9. Comparison between measured and computed water surface profiles for model $(1)(\mathrm{P}=20 \mathrm{~cm}$ and $\left.\mathrm{H}_{\mathrm{d}}=6.0 \mathrm{~cm}\right)$

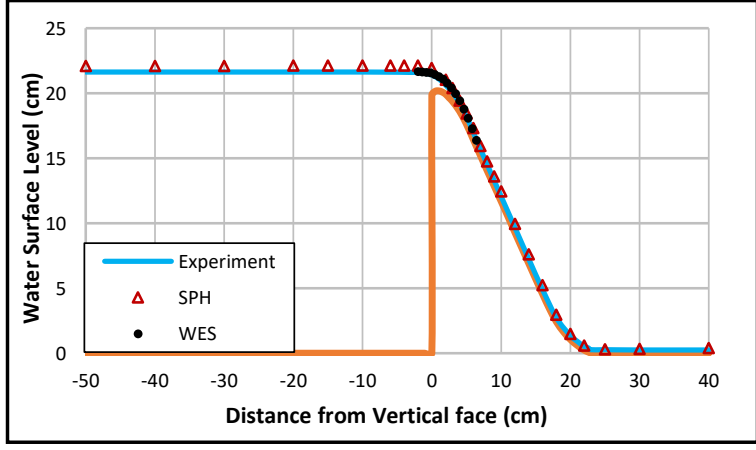

(a) Model No. (3), $\mathrm{H} / \mathrm{H}_{\mathrm{d}}=0.50$

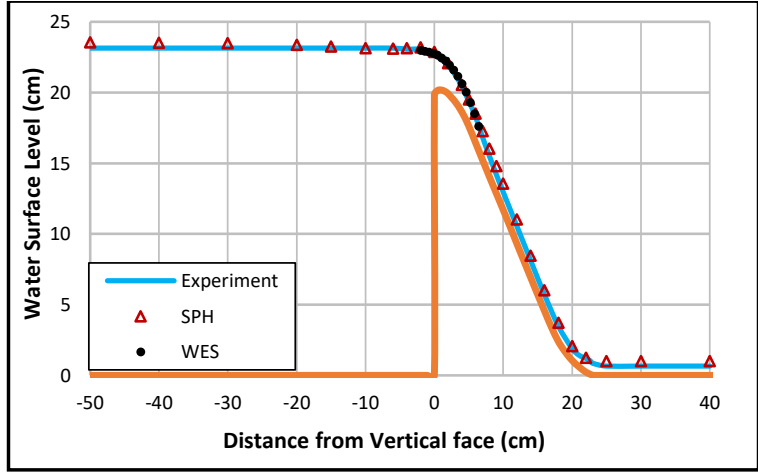

(b) Model No. (3), $\mathrm{H} / \mathrm{H}_{\mathrm{d}}=1.00$

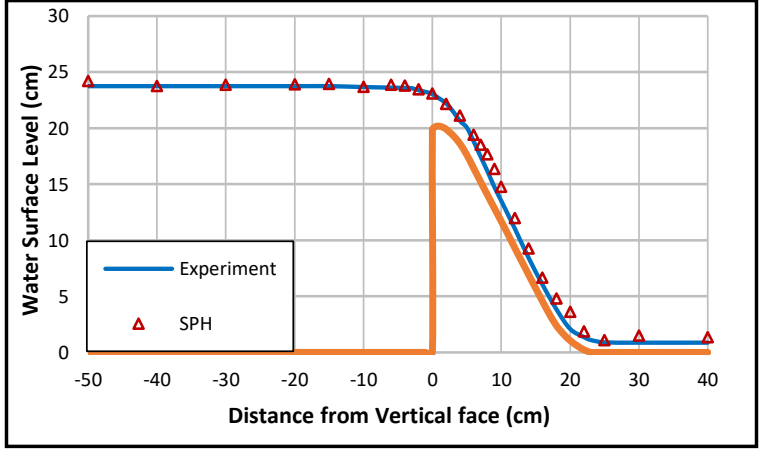

(c) Model No. (3), $\mathrm{H} / \mathrm{H}_{\mathrm{d}}=1.17$

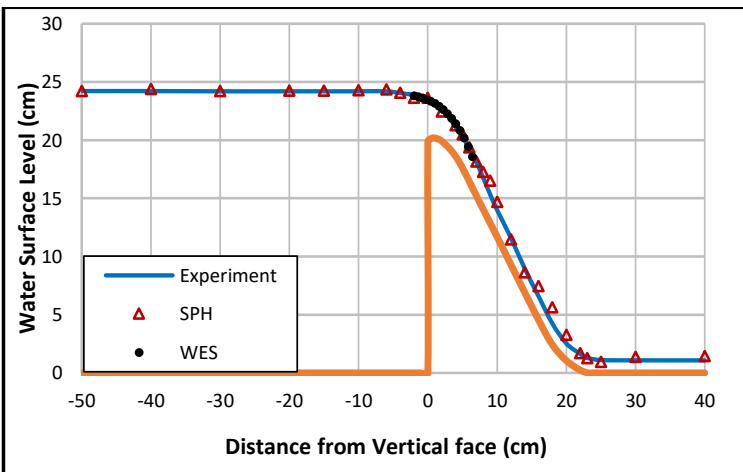

(d) Model No. (3), $\mathrm{H} / \mathrm{H}_{\mathrm{d}}=1.33$

Fig. 10. Comparison between measured and computed water surface profiles for model $(1)(P=20 \mathrm{~cm}$ and $\left.\mathrm{H}_{\mathrm{d}}=3.0 \mathrm{~cm}\right)$ 
Figures (8-10) show the comparison of the SPH results with the measured water surface profile. For all the runs, the free water surface profile obtained is acceptable and has the expected shape. The results show that the surface of the water closely follows the curvature of the crest, the straight portion of the face (rear), and the curvature of the toe. Additionally, the water depth over the entire spillway profile decreases as the approaching heads decrease and the overall smooth surface of the water develops especially, at the transition points in the spillway surface curvature. The experimental results of the USACE-WES are also shown for the sake of additional comparison. The results of the different pressure heads indicated that the water surface profiles obtained from SPH modeling are similar to those of the USACE published data.

For model No. 1, the maximum absolute difference between the measured and computed results of the water surface profile does not exceed $4.63 \%$ for all head ratios of $\left(\mathrm{H} / \mathrm{H}_{\mathrm{d}}\right)$ except for the toe region which reaches $10.30 \%$. For all models, the maximum absolute difference between the measured and computed results of the water surface profile does not exceed $3.68 \%$ for all head ratios of $\left(\mathrm{H} / \mathrm{H}_{\mathrm{d}}\right)$ in the crest region and does not exceed $6.41 \%$ for all head ratios of $\left(\mathrm{H} / \mathrm{H}_{\mathrm{d}}\right)$ in the rear region. While the maximum discrepancy between the measured and computed water surface profile results reached $10.59 \%$ for the most extreme cases in the toe region. The very close profiles show that there is quite good agreement between the measured and computed water surface profiles, especially in the crest region. Small discrepancies prevail in the downstream region of the spillway, which may be attributed to high velocity and turbulent flow.

\subsection{Comparison between Numerical} Methods:

\subsubsection{CFD modeling}

The CFD, which is a form of numerical modeling is developed to solve fluid flow problems. This type includes applications involving fluid-solid interaction, for example, the flow of water in a river or hydraulic structures [27]. This approach was gradually accepted by the Hydraulic/Dam Engineering Community not only as a research tool within research institutions [28] but also as a practical design tool [29]. With this complimentary use of CFD techniques and hydraulic modeling on a physical scale, experimental models have become essential for validating CFD modeling, [30]. Flow3D program was used to develop numerical models for the experimental models in order to study the water surface profile along the centerline of the spillway surface. Based on the literature review and the recommendations of researchers, the results obtained experimentally and numerically by SPH are compared with the CFD results in order to be more reassuring from the results.

\subsubsection{Water Surface Profile:}

Water surface profile was investigated from upstream to downstream of spillways along the centerline of the spillway surface. The results of experimental and numerical modeling (SPH and CFD) were plotted and compared for finding the convergences and divergences of the results. It's worth mentioning, that the experimental results were used as a comparison baseline. The following pressure heads are applied, based on the ratios of design head $(0.50,1.00,1.17$, and 1.33). 
Rizgar Ahmed Karim, Jowhar Rasheed Mohammad / Tikrit Journal of Engineering Sciences (2021) 28(2): 137-151.

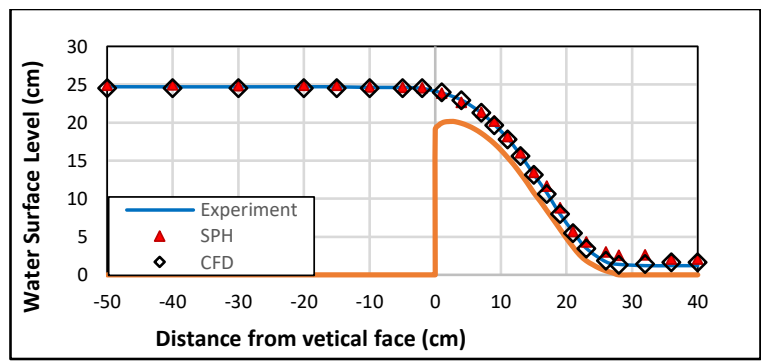

(a) Model No.1, $\mathrm{H} / \mathrm{H}_{\mathrm{d}}=0.50$

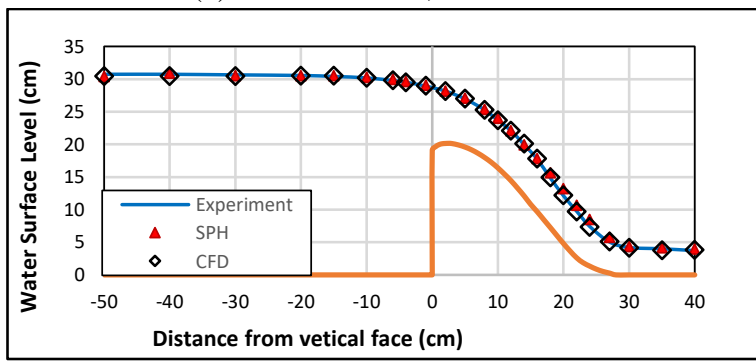

(c) Model No.1, $\mathrm{H} / \mathrm{H}_{\mathrm{d}}=1.17$

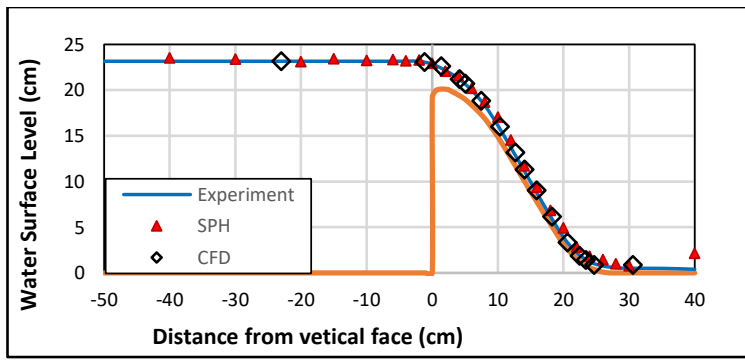

(a) Model No. $2, \mathrm{H} / \mathrm{H}_{\mathrm{d}}=0.50$

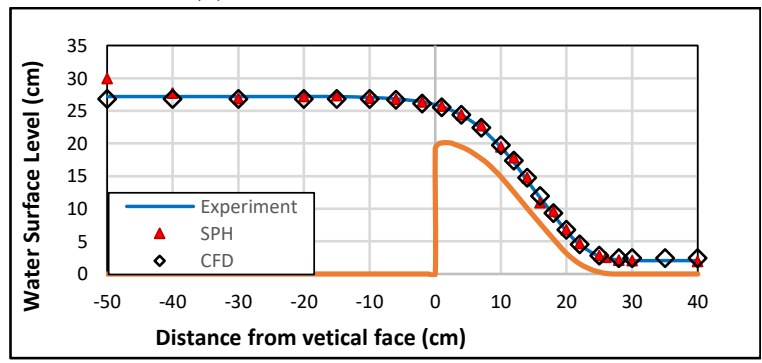

(c) Model No. $2, \mathrm{H} / \mathrm{H}_{\mathrm{d}}=1.17$

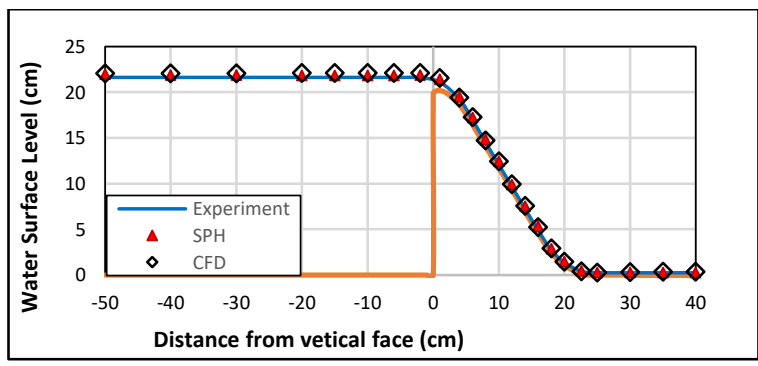

(a) Model No. $3, \mathrm{H} / \mathrm{Hd}=0.50$

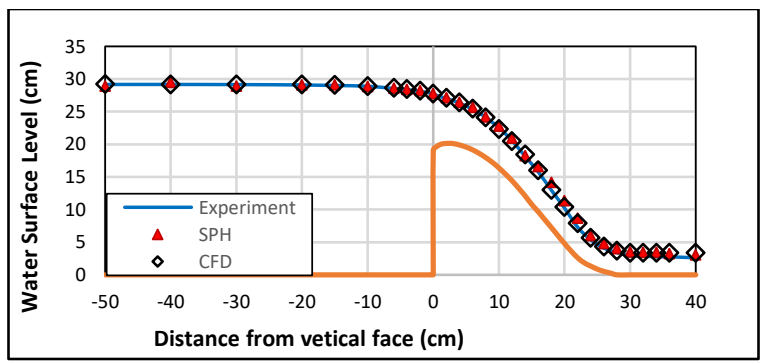

(b) Model No.1, $\mathrm{H} / \mathrm{H}_{\mathrm{d}}=1.00$

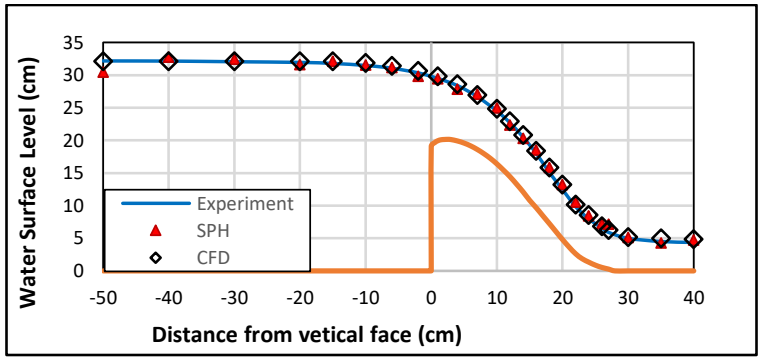

(d) Model No.2, $\mathrm{H} / \mathrm{H}_{\mathrm{d}}=1.33$

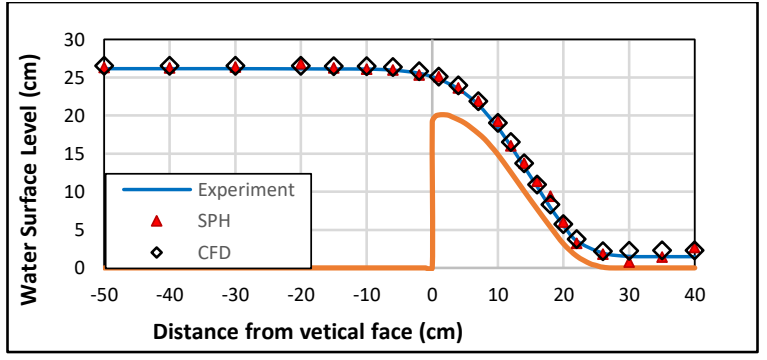

(b) Model No. 2, H/H $=1.00$

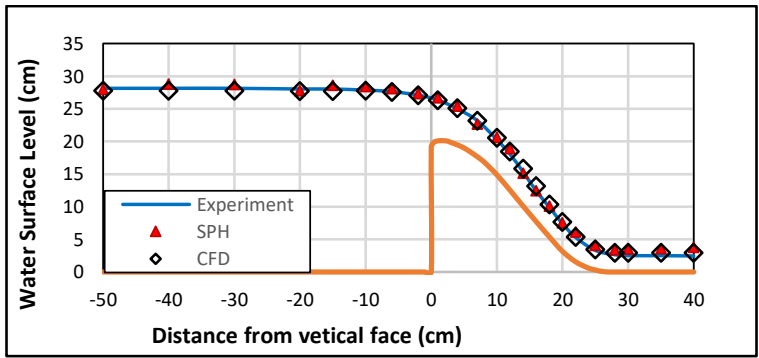

(d) Model No. 2, H/Hd=1.33

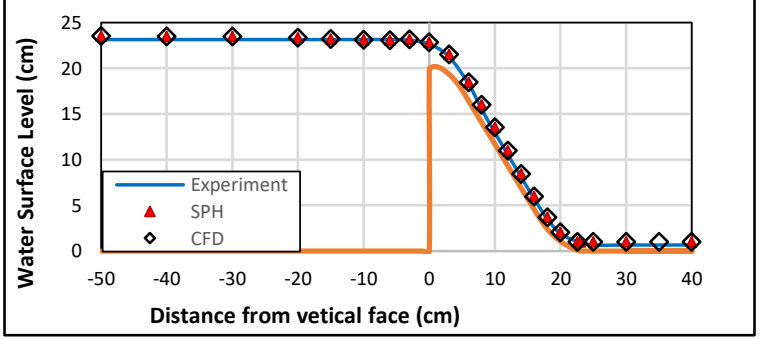

(b) Model No. 3, H/Hd = 1.00 


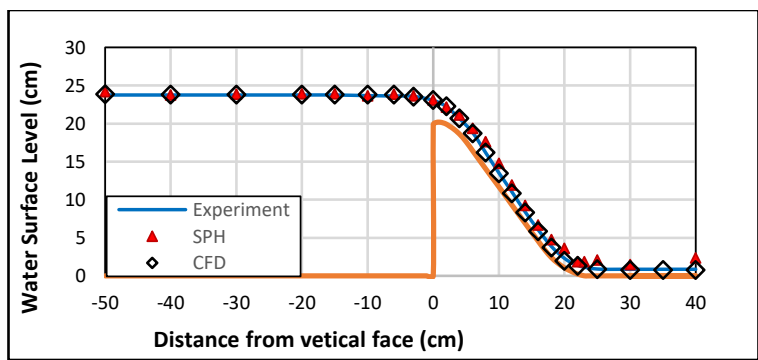

(c) Model No. 3, $\mathrm{H} / \mathrm{H}_{\mathrm{d}}=1.17$

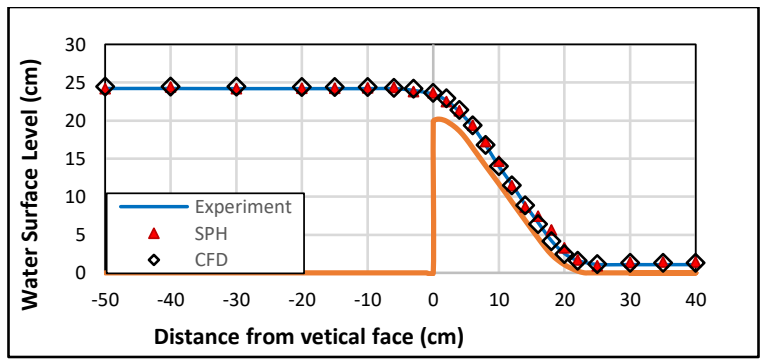

(d) Model No. 3, $\mathrm{H} / \mathrm{H}_{\mathrm{d}}=1.33$

Fig. 11. Comparison of experimental with numerical methods (SPH and CFD) for water surface

The profiles of free water surfaces shown in Figure (11) include the measurements of water flow elevations that are experimentally recorded and numerically computed. From Figure (11), it can be seen that the water surfaces simulated by numerical models, SPH and CFD, are in good agreement with those experimentally measured, especially at the crest and rear region, but some discrepancies take notice at the toe region of the spillway surface. It should be noted that the SPH technique can simulate the free water surface for ogee-crested spillways consistently.

For most accurate details, the spillway surface was divided into three regions of the crest, rear and toe regions. Comparison results reveal that the absolute maximum difference between experimental and SPH results does not exceed $2.04 \%$ in the crest region and $7.03 \%$ in the rear region, while in the toe region reached $10.59 \%$. Whereas, the maximum absolute difference between experimental and CFD results does not exceed $2.22 \%$ in the crest region and $4.73 \%$ in the rear region, while in the toe region is reaches $10.61 \%$. Discrepancies in the water surface occur in the high velocity and heavy turbulence area near the toe region. Thus, it should be noted that the SPH technique can consistently simulate the free water surface for the ogee spillway, also such precise results indicate that the SPH techniques can be used as an alternative to experiments and CFD approaches for simulating the water surface profile.

\section{Conclusions}

An open boundary condition in the SPH code was developed and in SPHysics code in special has been successfully accomplished with good performance.

The maximum absolute difference between the measured and computed results of the water surface profile, for all head ratios of $\left(\mathrm{H} / \mathrm{H}_{\mathrm{d}}\right)$, does not exceed $2.04 \%$ in the crest region and $7.03 \%$ in the rear region, while the maximum discrepancy between the measured and computed water surface profile results reaches $10.59 \%$ for the most extreme cases in the toe region.

The maximum absolute difference between experimental and CFD results does not exceed $2.22 \%$ in the crest region, $4.73 \%$ in the rear region, while in the toe region it reaches $10.61 \%$. Discrepancies in the water surface occur in the high velocity and heavy turbulence area near the toe region

SPH technique has been able to successfully model a water surface profile for a variety of upstream water heads as compared to experimental model testing.

\section{Reference:}

[1] Engineers, U.A.C.o., Corps of Engineers hydraulic design criteria. 1952, Waterways Experiment Station Vicksburg, Miss.

[2] Johnson, M.C. and B.M.J.J.o.h.e. Savage, Physical and numerical comparison of flow 
over ogee spillway in the presence of tailwater. 2006. 132(12): p. 1353-1357.

[3] Kanyabujinja, N.P., CFD modeling of ogee spillway hydraulics and comparison with physical model tests. 2015, Stellenbosch: Stellenbosch University.

[4] Liu, G.-R., Meshfree methods: moving beyond the finite element method. 2009: Taylor \& Francis.

[5] Gingold, R.A. and J.J.J.M.n.o.t.r.a.s. Monaghan, Smoothed particle hydrodynamics: theory and application to non-spherical stars. 1977. 181(3): p. 375389.

[6] Lucy, L.B., A Numerical Approach to Testing the Fission Hypothesis. 82 (12): 1013-1924. 1977, December.

[7] Dalrymple, R.A. and O. Knio. SPH modeling of water waves. in Coastal dynamics' 01. 2001.

[8] Monaghan, J.J., A.J.J.o.w. Kos, port, coastal, and o. engineering, Solitary waves on a Cretan beach. 1999. 125(3): p. 145-155.

[9] Monaghan, J.J.J.J.o.c.p., Simulating free surface flows with SPH. 1994. 110(2): p. 399406.

[10] Khayyer, A., H. Gotoh, and S.J.C.E. Shao, Corrected incompressible SPH method for accurate water-surface tracking in breaking waves. 2008. 55(3): p. 236-250.

[11] Mokos, A., et al., Simulating wave overtopping on a complex coastal structure using SPH. 2020. 8(1): p. 55-65.

[12] Canor, T. and V.J.I.j.f.n.m.i.e. Denoël, Transient Fokker-Planck-Kolmogorov equation solved with smoothed particle hydrodynamics method. 2013. 94(6): p. 535553.

[13] Amicarelli, A., et al., A Smoothed Particle Hydrodynamics model for 3D solid body transport in free surface flows. 2015. 116: p. 205-228.

[14] Liu, M., Z.J.S.C.P. Zhang, Mechanics, and Astronomy, Smoothed particle hydrodynamics (SPH) for modeling fluidstructure interactions. 2019. 62(8): p. 984701

[15] Wang, Z.-B., et al., An overview of smoothed particle hydrodynamics for simulating multiphase flow. 2016. 40(23-24): p. 96259655.

[16] Szewc, K., Development of smoothed particle hydrodynamics approach for modelling of multiphase flows with interfaces. 2013, Université de Lorraine.
[17] Albano, R., et al., Modelling large floating bodies in urban area flash-floods via a Smoothed Particle Hydrodynamics model. 2016. 541: p. 344-358.

[18] Lind, S.J., P. Stansby, and B.D.J.J.o.C.P. Rogers, Incompressible-compressible flows with a transient discontinuous interface using smoothed particle hydrodynamics (SPH). 2016. 309: p. 129-147.

[19] Violeau, D. and B.D.J.J.o.H.R. Rogers, Smoothed particle hydrodynamics (SPH) for free-surface flows: past, present and future. 2016. 54(1): p. 1-26.

[20] Ghazi, B., et al., Numerical investigation of hydraulic characteristics and prediction of cavitation number in Shahid Madani Dam's Spillway. 2019. 7(4): p. 323-332.

[21] Alhashimi, D.S.A.M.J.I.J.o.S.E. and T. Research, CFD modeling of flow over ogee spillway by using different turbulence models. 2013. 2: p. 1682-1687.

[22] Usta, E.J.U.m.s.t., METU, Ankara, TURKEY, Numerical investigation of hydraulic characteristics of Laleli Dam spillway and comparison with physical model study. 2014.

[23] Gomez-Gesteira, M., et al., SPHysicsdevelopment of a free-surface fluid solverPart 1: Theory and formulations. 2012. 48: p. 289-299.

[24] Khatsuria, R.M., Hydraulics of spillways and energy dissipators. 2004: CRC Press.

[25] Maynord, S.T., General spillway investigation: Hydraulic model investigation. 1985.

[26] Jafari-Nodoushan, E., et al., Meshless particle modelling of free surface flow over spillways. 2016. 18(2): p. 354-370.

[27] Chanel, P.G., An evaluation of computational fluid dynamics for spillway modeling. 2009.

[28] Savage, B.M. and M.C.J.J.o.h.e. Johnson, Flow over ogee spillway: Physical and numerical model case study. 2001. 127(8): p. 640-649.

[29] Gessler, D., CFD modeling of spillway performance, in Impacts of Global Climate Change. 2005. p. 1-10.

[30] Yakun, G., et al., Numerical modelling of spillway flow with free drop and initially unknown discharge. 1998. 36(5): p. 785-801. 